\title{
ESTUDO COMPARATIVO DE CÁPSULAS CONTENDO AMOXICILINA OBTIDAS DEALGUMAS FARMÁCIAS MAGISTRAIS
}

\author{
PAULO, Glauber Dias; MAZZUCO, Ana Paula; RODOLPHO, Juliana Cristina. Farmacêuticos graduados \\ pelo Centro Universitário de Araraquara - Uniara. \\ SALGADO, Hérida Regina Nunes. Docente da Faculdade de Ciências Farmacêuticas da Universidade \\ Estadual Paulista - Unesp. \\ MORENO, Andréia de Haro. Docente do Centro Universitário de Araraquara - Uniara. E-mail: \\ ahmoreno@uniara.com.br.
}

\begin{abstract}
RESUMO
A amoxicilina é um antibiótico semissintético pertencente à classe das penicilinas, ativo contra bactérias grampositivas e gram-negativas, empregado no tratamento de diversas infecções, sendo um dos fármacos mais utilizados na antibioticoterapia (dose usual de $500 \mathrm{mg}$ ). De acordo com a RDC n. ${ }^{\circ} 87 / 2008$, as farmácias devem analisar seus produtos terminados, a fim de assegurar alguns parâmetros de qualidade essenciais, tais como peso médio, tempo de dissolução e teor de princípio ativo. O objetivo do presente trabalho foirealizar o estudo comparativo de três preparações magistrais contendo amoxicillin $500 \mathrm{mg}$ (cápsulas) e comparar os resultados com aqueles obtidos com o medicamento genérico. A metodologia utilizada foi a preconizada pela Farmacopeia Brasileira para amoxicilina. Das três preparações magistrais analisadas, todas foram aprovadas quanto ao peso médio, porém apenas uma apresentou conformidade com o tempo de dissolução e com o teor $(81,30 \pm 0,98 \%$ e $91,65 \pm 0,72 \%$, respectivamente). Os resultados indicaram a necessidade de um monitoramento rigoroso por parte das farmácias magistrais, a fim de assegurar a correta dose do fármaco e a eficácia terapêutica, na escolha dos excipientes e dos procedimentos corretos de pesagem, homogeneização e encapsulação, bem como a avaliação da pureza e integridade das matérias-primas.
\end{abstract}

Palavras-chave: Cápsulas de amoxicilina; Farmácias magistrais; Controle de qualidade.

\begin{abstract}
Amoxillin is a semisynthetic antibiotic classified as penicillin of wide action spectrum against gram-positive and gram-negative bacteria, largely used in the treatments of several infections. Besides, amoxicillin is a drug widely used in clinical treatment (the usual dosage is $500 \mathrm{mg}$ ). According to RDC n.87/2008, in order to monitoring the manipulation process, pharmacies must analyze their pharmaceutical formulations to assure some important quality parameters, such as average weight, dissolution time and assay, to guarantee the drug concentration and therapeutic efficacy. The objective of this work was to develop a comparative study of three pharmaceutic formulations containing amoxicillin $500 \mathrm{mg}$ (capsules) and to compare the results to those obtained from the generic drug. The analysis was carried out according to Brazilian Pharmacopoeia for amoxicillin. Although the 3 magistral preparations analyzed have been approved in average weight determination, only one pharmaceutical formulation presented satisfactory results for time dissolution and assay determinations $(81,30 \pm 0,98 \%$ and $91,65 \pm 0,72 \%$, respectively). The results showed the necessity of a strict quality monitoring by the pharmacies to assure the correct drug dosage and its therapeutic efficacy. The selection of excipients and the weight, blend and encapsulation procedures are very important, as well as the evaluation of the purity and integrity of raw materials.
\end{abstract}

KEYwORDS: Amoxicillin capsules; Pharmacies; Quality control. 


\section{INTRODUÇÃ̃o}

Antibióticos são substâncias que possuem a capacidade de interagir com micro-organismos e impedir ou dificultar a manutenção de suas células vivas. As primeiras substâncias descobertas eram produzidas por fungos e bactérias; porém, atualmente são sintetizadas e/ou modificadas em laboratórios farmacêuticos (MARTINDALE, 2006).

Esses fármacos são considerados valiosos na terapia de doenças infecciosas e apresentam diferenças quanto às propriedades físicas, químicas e farmacológicas, no espectro antibacteriano e nos mecanismos de ação. O desenvolvimento de compostos capazes de intervir nos ciclos de vida desses micro-organismos foi facilitado devido ao conhecimento dos mecanismos de replicação dos mesmos (PETRI, 2006). Os agentes antimicrobianos estão entre os mais notáveis exemplos dos avanços da medicina moderna. Muitas doenças infecciosas, outrora consideradas incuráveis e letais, são, atualmente, passíveis de tratamento com apenas alguns comprimidos (NICHOLS, 2006).

Porém, a prescrição excessiva e o uso inapropriado de antibióticos propiciam aumento significativo na prevalência de patógenos resistentes. O contínuo desenvolvimento da resistência nos micro-organismos exige que as farmácias magistrais mantenhamum nível de qualidade e eficácia ainda maior desse grupo de fármacos (PETRI, 2006).

De acordo com a RDC n. ${ }^{\circ} 87$, de 21 de novembro de 2008 (BRASIL, 2008), a realização do controle de qualidade pelas farmácias magistrais é de suma importância para que a qualidade microbiológica e físico-química dos insumos utilizados e dos produtos acabados seja assegurada, garantindo eficácia, segurança e credibilidade dos medicamentos manipulados e dispensados à população (GIL \& MACHADO, 2005).

Para a obtenção de medicamentos com qualidade, todo processo envolvido na produção deve ser monitorado, incluindo: controle do meio ambiente, controle da fabricação e controle final do produto acabado (BRASIL, 2008). A contaminação cruzada é um dos pontos críticos para a manutenção da qualidade dos medicamentos. Os fatores predisponentes da ocorrência são: utilização de equipamentos e vidrarias mal lavados, presença de pó suspenso no ar e as condições relacionadas ao próprio manipulador (NUNAN et al., 2003). O conhecimento, disciplina, cumprimento de procedimentos e atenção para a limpeza e higienização são quesitos a ser observados para que a contaminação cruzada tenha menor incidência (FERREIRA, 2002).

A farmácia tem por obrigação submeter, através de amostragem adequada, os produtos acabados aos ensaios farmacopeicos exigidos, podendo decidir por realizar ou terceirizar os testes de teor de princípio ativo e pureza microbiológica. A empresa responsável por realizá-los deve estar tecnicamente capacitada para esse fim. As análises exigidas pela RDC n. ${ }^{\circ}$ 87/2008 (BRASIL, 2008) são: peso médio, propriedades organolépticas, $\mathrm{pH}$, friabilidade, dureza, desintegração, grau ou teor alcoólico, densidade, volume, viscosidade, teor do princípio ativo e pureza microbiológica, quando aplicáveis ao produto a ser analisado.

Outro aspecto muito importante na qualidade dos medicamentos é a avaliação do teste de dissolução in vitro (PINHO \& STORPIRTIS, 2001). Segundo alguns autores, a eficácia clínica de uma preparação farmacêutica não pode ser atribuída somente à atividade intrínseca da substância ativa. Os componentes da formulação e os processos de fabricação podem afetar o comportamento do medicamento no organismo, dando origem a casos de ineficácia e de intoxicações (KOHLER et al., 2009). Desse modo, os estudos de dissolução in vitro constituem um dos instrumentos essenciais para avaliação dessas propriedades nas formulações, sendo que o perfil de dissolução (percentagem de fármaco dissolvido versus tempo) é da maior importância para estudar o processo cinético de dissolução e, ao mesmo tempo, fornece dados valiosos para se determinar a uniformidade entre lotes e a existência ou não de correlação dos resultados in vitro e in vivo (AGUIAR et al., 2005; MALESUIK et al., 2006; LINSBINSKI et al., 2008). 
Entretanto, alguns fatores dificultam a prática do controle de qualidade pelas farmácias magistrais, tais como: alto custo, necessidade de investimento inicial para adequação de área física e aquisição de equipamentos básicos para a realização dos testes mínimos exigidos, necessidade de treinamento contínuo de pessoas, complexidade de algumas análises, entre outros.

Dessa forma, apesar do grande aumento no número de farmácias magistrais, verificado nos últimos anos, muitas ainda não conseguiram implantar satisfatoriamente as normas de Boas Práticas de Manipulação, nem realizar o controle de qualidade de seus produtos. Assim, aliado ao elevado número de prescrições e consumo de antibióticos no Brasil, além do surgimento exponencial de novas cepas resistentes, o objetivo do presente trabalho foi realizar o controle de qualidade de medicamentos manipulados (cápsulas) contendo amoxicilina $500 \mathrm{mg}$, obtidos de algumas farmácias magistrais de São Carlos, SP.

\section{Metodologia}

As análises foram realizadas segundo metodologia e procedimentos preconizados pela Farmacopeia Brasileira (2001) para amoxicilina matéria-prima e produto acabado (cápsulas).

\section{Obtenção das amostras}

Foram obtidas quatro amostras de amoxicilina 500 mg (cápsulas), sendo três manipuladas em diferentes farmácias magistrais de São Carlos, SP (amostras B, C e D), e uma amostra comercial (medicamento genérico, A). Os excipientes e adjuvantes empregados nas formulações magistrais foram: amido, lactose e aerosil (amostra B), amido, talco, estearato de magnésio e lauril sulfato de sódio (amostra C) e amido, talco, aerosil e celulose microcristalina (amostra D).

Como substância de referência, foi utilizada amoxicilina trihidratada (potência declarada de $1054,34 \mu \mathrm{g} / \mathrm{mg}$ ), fornecida pela Ariston Indústria Química e Farmacêutica Ltda. (São Paulo, SP).

\section{Ensaios realizados}

Segundo exigências da RDC n. ${ }^{\circ} 87 / 2008$ (BRASIL, 2008), foram realizados os ensaios de peso médio, tempos de desintegração e de dissolução, identificação e teor de princípio ativo em todas as amostras de medicamento contendo amoxicilina 500 mg. As metodologias empregadas na execução das análises foram preconizadas pela Farmacopeia Brasileira (2001). Todos os reagentes utilizados foram de grau analítico.

\section{Peso médio}

Foram pesadas individualmente 20 cápsulas de cada amostra contendo amoxicilina $500 \mathrm{mg}$ e determinados os pesos médios. Pode-se tolerar variação de pesos individuais em relação ao peso médio de $\pm 7,5 \%$ para cápsulas com peso médio superior a $300 \mathrm{mg}$ (FARMACOPEIABRASILEIRA, 2001).

\section{Identificação}

A identificação foi realizada por cromatografia em camada delgada, empregando fase móvel constituída de metanol:clorofórmio:água:acetona $(9: 8: 3: 1 ; \mathrm{v} / \mathrm{v}) \mathrm{e}$ revelador ninidrina alcoólica $0,3 \%(\mathrm{p} / \mathrm{v})$.

As amostras e a substância de referência foram preparadas em ácido clorídrico $0,1 \mathrm{~mol} / \mathrm{L}$ na concentração de $0,4 \%$ (p/v) e aplicados $5 \mu \mathrm{Lem}$ placa de sílica-gel G 60. Após o desenvolvimento do cromatograma, a placa foi pulverizada com solução de ninidrina $0,3 \%$ e levada à estufa a $110^{\circ} \mathrm{C}$ por 15 minutos para o desenvolvimento das manchas.

\section{Teor (determinação da potência por ensaio microbiológico)}

Determina-se a potência (atividade) de um antibiótico comparando a dose que inibe o crescimento do micro-organismo sensível com a dose da preparação-padrão do antibiótico que produz inibição similar (PINTO et al., 2003). Neste trabalho, foi realizado ensaio microbiológico (método de difusão em ágar, cilindros em placas) na determinação da potência de amoxicilina. Foram utilizadas vidrarias e soluções estéreis, sendo todo o procedimento realizado em capela de fluxo laminar. 
Amoxicilina, substância de referência, foi dissolvida em água estéril de modo a obter solução na concentração de $1 \mathrm{mg} / \mathrm{mL}$. Para cada uma das amostras, 20 cápsulas foram pesadas e os conteúdos, removidos para posterior nova pesagem. Após homogeneização do conteúdo, uma quantidade de pó equivalente a $100 \mathrm{mg}$ de amoxicilina, exatamente pesada, foi transferida para frasco volumétrico de 100 mL e diluída com tampão fosfato de potássio $0,1 \mathrm{~mol} /$ L, estéril, pH 8, obtendo soluções de trabalho na concentração de $1 \mathrm{mg} / \mathrm{mL}$. Para a completa solubilização das amostras, as soluções foram submetidas ao banho de ultrassom por 15 minutos.

De acordo com a Farmacopeia Brasileira (2001), a faixa de concentração das soluções de referência e amostras deve ser de $0,05 \mu \mathrm{g} / \mathrm{mL}$ a $0,2 \mu \mathrm{g} / \mathrm{mL}$. Assim, foram empregadas no ensaio as concentrações de 0,05 $\mu \mathrm{g} / \mathrm{mL}, 0,1 \mu \mathrm{g} / \mathrm{mL}$ e $0,2 \mu \mathrm{g} / \mathrm{mL}$ (concentrações de trabalho), todas preparadas em tampão fosfato de potássio $0,1 \mathrm{~mol} / \mathrm{L}$, estéril, $\mathrm{pH} 8$. Dessa forma, foram transferidos volumes de 50, 100 e $200 \mu \mathrm{L}$ de solução a $10 \mu \mathrm{g} / \mathrm{mL}$ de amoxicilina substância de referência e amostras (obtidas a partir das soluções preparadas a $1 \mathrm{mg} / \mathrm{mL}$ ) para balões volumétricos de $10 \mathrm{~mL}$, completando o volume com solução tampão fosfato pH 8,0.

O micro-organismo utilizado como inóculo foi o Micrococcus luteus ATCC 9341, cultivado 24 horas antes da execução do ensaio, e o meio de cultura, ágar Antibiótico n. ${ }^{\circ} 11$ (21 mL para a camada base e $4 \mathrm{~mL}$ para a camada superfície). O volume do inóculo foi de $0,5 \mathrm{~mL} / 100 \mathrm{~mL}$, obtido de solução fisiológica estéril a $25 \%$ de transmitância a $580 \mathrm{~nm}$ (suspensão bacteriana). Após solidificação da camada inoculada (superfície), volumes de $200 \mu \mathrm{L}$ das soluções $(0,05 ; 0,1 ; 0,2 \mu \mathrm{g} /$ $\mathrm{mL}$ ) foram depositados nos cilindros dispostos sobre o meio inoculado. Aincubação foi realizada a $32-35^{\circ} \mathrm{C}$ durante 21 horas, e, após, realizou-se a leitura dos halos com paquímetro digital ( $\mathrm{mm}$ ) e os cálculos das potências, segundo a equação de Hewitt (1977).

\section{Tempo de desintegração}

O teste de desintegração determina se a cápsula desintegra dentro do limite de tempo especificado na monografia de cada forma medicamentosa, quando unidades, em número especificado, são submetidas às condições experimentais descritas.

Foi utilizado desintegrador Nova Ética Modelo 301/ AC (São Paulo, SP) contendo uma cápsula em cada um dos seis tubos da cesta e acionado o aparelho, utilizando água mantida a $37^{\circ} \mathrm{C}$ como líquido de imersão. Utilizou-se uma tela com abertura de $2 \mathrm{~mm}$, de arame de aço inoxidável adaptada à tampa da cesta. As cápsulas foram observadas após 45 minutos.

\section{Tempo de dissolução}

O teste de dissolução determina a porcentagem da quantidade de princípio ativo, declarada no rótulo do produto, liberada no meio de dissolução, dentro do período de cada produto, quando o mesmo é submetido à ação de aparelhagem específica, sob condições experimentais descritas.

Quando um único tempo for especificado na monografia do produto, como é o caso da amoxicilina, o mesmo representa o tempo máximo dentro do qual deve ser dissolvida a quantidade mínima, em porcentagem, de princípio ativo, estabelecida na mesma. Não obstante, se esta quantidade for obtida em tempo menor que o especificado, o teste pode ser dado por terminado ao final desse tempo. Quando mais de um tempo for especificado na monografia, devem ser tomadas alíquotas ao final de cada tempo indicado.

Foi utilizado dissolutor Nova Ética Modelo 299/1 (São Paulo, SP) e adicionado o volume de meio de dissolução especificado na monografia do produto $(900$ $\mathrm{mL}$ de água destilada), convenientemente desaerado, ao recipiente da aparelhagem de dissolução. A temperatura foi mantida a $37^{\circ} \mathrm{C} \pm 0,5^{\circ} \mathrm{C}$, retirando-se o termômetro antes de iniciar a agitação.

As amostras foram colocadas nas cestas e imediatamente foi dado início à agitação, conforme velocidade pré-estabelecida (100 rpm). Ao final do tempo especificado (90 minutos), alíquotas foram retiradas do meio de dissolução, filtradas e diluídas em água, até concentração teórica adequada de 0,01\% (p/v). As absorvâncias das soluções foram 
medidas em $272 \mathrm{~nm}$, utilizando o mesmo solvente para zerar o aparelho, e as quantidades de amoxicilina dissolvida no meio, calculadas, comparando as leituras obtidas coma solução de referência na concentração de $0,01 \%$ (p/v) preparada no mesmo solvente. Como tolerância, não menos que $80 \%$ da quantidade declarada de amoxicilina deve dissolver em 90 minutos.

\section{Resultados E Discussão \\ Peso médio}

Segundo a Farmacopeia Brasileira, a variação individual de peso permitida para cápsulas com peso inferior ao valor declarado de $500 \mathrm{mg}$ é de $\pm 7,5 \%$, em relação ao peso médio. Os resultados obtidos na determinação do peso médio estão apresentados na Tabela 1.

Tabela 1 - Pesos médios obtidos para os medicamentos analisados contendo amoxicilina 500 mg.

\begin{tabular}{lcccc} 
Parâmetros & Amostra A & Amostra B & Amost ra C & Amostra D \\
\hline Peso médio (g) & 0,6924 & 0,8605 & 0,7439 & 0,8299 \\
Peso máximo obtido (g) & 0,7225 & 0,8864 & 0,7848 & 0,8540 \\
Desvio padrão máximo (\%) & 4,35 & 3,01 & 5,50 & 2,90 \\
Peso mínimo obtido (g) & 0,6712 & 0,8296 & 0,6938 & 0,8096 \\
Desvio padrão mínimo (\%) & 3,06 & 3,59 & 6,73 & 2,45
\end{tabular}

Fonte: Dados de pesquisa

Todas as amostras estão de acordo com as especificações farmacopeicas em relação ao peso médio. No entanto, observou-se que as cápsulas da amostra D apresentaram distribuição de peso mais homogêneo, com menores valores de desvio-padrão.

\section{Identificação}

As amostras foram identificadas por cromatografia em camada delgada. Todas apresentaram mancha principal, correspondente em posição, cor e intensidade em relação à substância de referência, e percorreram praticamente as mesmas distâncias de eluição, indicando a presença do fármaco pesquisado. $\mathrm{O}$ fator de retenção médio calculado para as amostras em relação à substância de referência foi de 1,08 $\pm 0,01$, estando de acordo segundo o teste farmacopeico empregado.

\section{Teor (determinação da potência por ensaio microbiológico)}

Os ensaios de potência visam quantificar o teor de substância ativa em medicamentos. No que se refere às análises quantitativas, estas são utilizadas com o objetivo de estabelecer a concentração dos componentes essenciais presentes em uma determinada amostra (GIL \& MACHADO, 2005). Os resultados obtidos no ensaio microbiológico de amoxicilina estão representados na Tabela 2. 
Tabela 2 - Teores encontrados no doseamento por ensaio microbiológico de amoxicilina cápsulas 500 mg.

\begin{tabular}{cccc} 
Amostras & Valor encontrado $(\mathbf{m g}) *$ & Teor $(\%) *$ & CV (\%) \\
\hline A & 580,85 & 116,17 & 0,614 \\
B & 458,25 & 91,65 & 0,725 \\
C & 414,95 & 82,99 & 0,468 \\
D & 444,25 & 88,85 & 0,763
\end{tabular}

*cada valor é a média de 6 determinações

$* * \mathrm{CV}=$ coeficiente de variação

Fonte: Dados de pesquisa

Os resultados indicaram teores de fármaco bastante diferentes em relação ao medicamento genérico. De acordo com a Farmacopeia Brasileira, a potência deve ser de, no mínimo, 90,0\% e, no máximo, 120,0\% do valor declarado de amoxicilina. Assim, apenas o medicamento genérico (A) e uma amostra magistral foram aprovados (B), estando em conformidade com os teores exigidos.

\section{Tempo de desintegração}

A desintegração é definida, para os fins deste teste, como o estado no qual nenhum resíduo da unidade (cápsula), salvo fragmentos de revestimentos ou matriz de cápsula insolúvel, permanece na tela metálica do aparelho de desintegração. Consideram-se também como "desintegradas" as unidades que, durante o teste, se transformam em massa pastosa que não apresente fragmentos que permaneçam sobre a tela do aparelho (FARMACOPEIABRASILEIRA, 2001).

A Farmacopeia Brasileira preconiza o tempo máximo de desintegração de cápsulas duras de 45 minutos. Todas as amostras analisadas se apresentaram totalmente desintegradas após período máximo de dez minutos.

\section{Tempo de dissolução}

Uma vez que o objetivo da determinação do tempo de dissolução é verificar a quantidade de fármaco dissolvido no meio de dissolução após determinado tempo, a Farmacopeia Brasileira (2001) preconiza que, no tempo máximo de 90 minutos, no mínimo $80 \%$ de amoxicilina deve estar dissolvida. Nesse tipo de estudo deve ser considerado o teor de fármaco quantificado por metodologia analítica oficial e/ou validada. De acordo com os dados da Tabela 3, os resultados indicaram que somente as amostras Ae B apresentaram teores maiores que $80 \%$ de fármaco dissolvido após o teste. Nas amostras C e D os teores mais baixos podem estar relacionados a vários fatores, tais como teor menor das matérias-primas, presença de impurezas e mesmo possível interferência dos excipientes utilizados no preparo das cápsulas ou possíveis erros de cálculo, preparo ou pesagem. 
Tabela 3 - Resultados obtidos no teste de dissolução para as amostras analisadas de amoxicilina $500 \mathrm{mg}$.

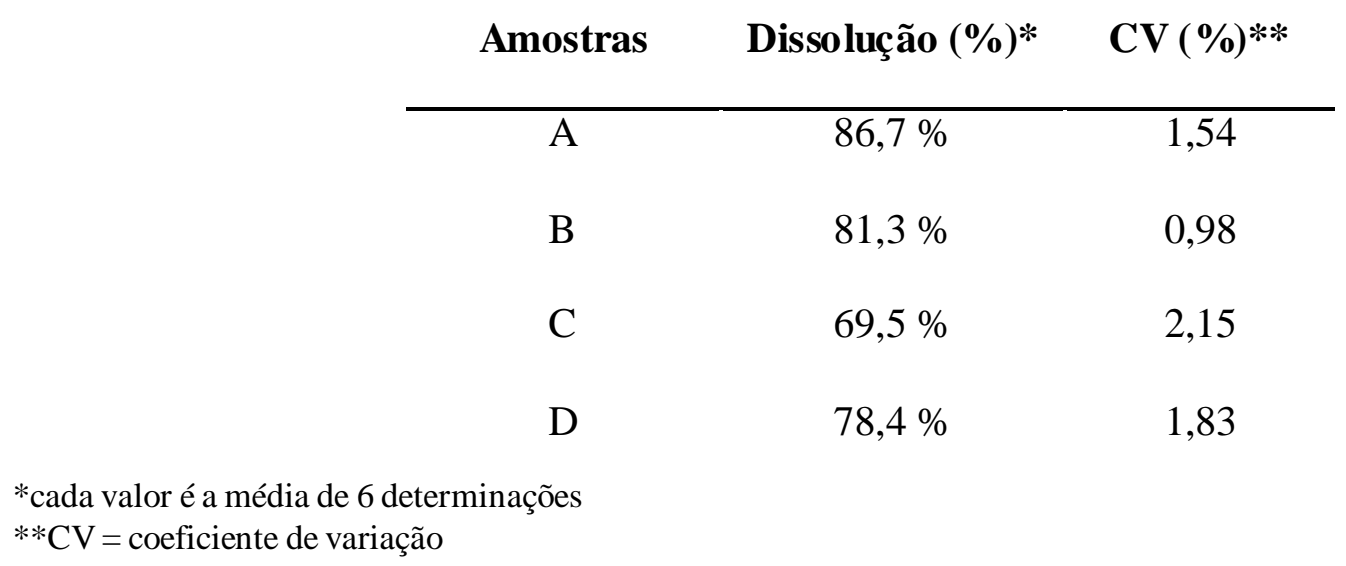

Fonte: Dados de pesquisa

A qualidade dos medicamentos compreende as técnicas e as atividades operacionais usadas para satisfazer as necessidades da qualidade. No setor farmacêutico, a importância e o rigor com o controle de qualidade são bem maiores devido aos aspectos morais e éticos que estão relacionados com a produção de medicamentos, pois qualquer falha no processo produtivo pode traduzir-se em risco para o paciente, podendo evoluir desde a ineficácia à toxicidade ou, eventualmente, à morte. A qualidade, a segurança e a eficácia dos produtos farmacêuticos consistem em constante preocupação por parte dos órgãos sanitários de todos os países, responsáveis pela definição dos parâmetros de qualidade, bem como pela fiscalização do seu cumprimento (NUNAN et al., 2003).

Em relação às amostras analisadas neste trabalho, pode-se verificar que, para a manipulação de medicamentos, com destaque aos antibióticos, se exige um controle de qualidade rigoroso durante a fase de pesagem dos princípios ativos, pois qualquer erro nesse procedimento acarretará resultados insatisfatórios para os principais testes propostos pela Farmacopeia Brasileira (2001), como ensaios de potência e dissolução.

Foram analisados diversos parâmetros de qualidade de amoxicilina cápsulas $500 \mathrm{mg}$, tais como peso médio, identificação, tempos de desintegração e de dissolução e doseamento. Na determinação do peso médio verifica-se a uniformidade de peso das unidades de um mesmo lote; porém, não está relacionado com a homogeneidade de distribuição do fármaco nas unidades individuais desse lote. Os limites de variação tolerados diminuem à medida que o peso médio ou valor nominal aumenta. Os resultados indicaram que todas as amostras se apresentaram de acordo em relação ao peso médio, segundo as especificações da Farmacopeia Brasileira (2001) (Tabela 1).

A identificação do fármaco é requerida para todas as formas farmacêuticas, utilizando-se métodos físicoquímicos ou químicos adequados. Os resultados do teste de identificação por cromatografia em camada delgada mostraram-se de acordo com o proposto pela farmacopeia, apresentando mancha principal correspondente em posição, cor e intensidade em relação à substância de referência, com fator de retenção de $1,08 \pm 0,01$.

O teste de desintegração é aplicado tanto a formas sólidas, como cápsulas, comprimidos e drágeas, como também plásticas (supositórios e óvulos), e relacionase indiretamente com a biodisponibilidade da forma farmacêutica, uma vez que não se preocupa em reproduzir exatamente as condições fisiológicas. O teste avalia somente o tempo necessário para que a forma farmacêutica em condições pré-estabelecidas se 
desintegre. Sabe-se que a resposta biológica a um fármaco é resultado de sua interação com os receptores celulares ou sistemas enzimáticos importantes. A magnitude da resposta relaciona-se com a concentração em seu local de ação e depende da dose administrada, da quantidade absorvida, da distribuição no local, da velocidade e da eliminação do organismo (FERREIRA, 2002). Assim, a liberação do conteúdo da forma farmacêutica para consequente solubilização nos fluidos biológicos é a primeira de todas essas etapas, sendo representada pelo teste oficial farmacopeico de desintegração, embora se reconheça que esse teste in vitro não guarde necessariamente relação com a ação in vivo da forma farmacêutica sólida, porém oferece um meio de controle para assegurar lote a lote o comportamento de uma formulação quanto à desintegração (NUNAN et al., 2003). De acordo com os resultados obtidos, as amostras foram todas aprovadas, apresentando-se totalmente desintegradas após período máximo de dez minutos.

A dissolução é o processo no qual o fármaco se dissolve em líquidos biológicos (meio aquoso), sendo considerada condição importante para a sua absorção sistêmica. $\mathrm{O}$ teste de dissolução in vitro é utilizado para medir a velocidade e a extensão da dissolução de uma substância em um meio aquoso simulatório gástrico ou entérico a $37^{\circ} \mathrm{C}$, na presença do excipiente contido no produto farmacêutico. Os resultados do teste de dissolução podem ser considerados um prognóstico da biodisponibilidade, porém, não substitui seus ensaios; os resultados obtidos através desses testes podem dar relativa segurança de que o fármaco será liberado de uma mesma forma farmacêutica in vitro como in vivo e, posteriormente, absorvido. Assim, considera-se que o teste de dissolução é um instrumento importante na avaliação da liberação de um fármaco a partir de uma formulação (FERREIRA, 2002).

Durante o ensaio, é importante verificar a possível interferência dos excipientes na liberação do fármaco. O tradicional conceito de excipiente como sendo meras substâncias capazes de facilitar a administração e estabilizar a preparação mudou ao longo dos anos; são considerados, atualmente, constituintes essenciais, que garantem o desempenho, a segurança do medicamento e a obtenção do efeito terapêutico, devendo ser, portanto, objetos de importantes considerações durante a fase de pré-formulação (ANTUNES, 2002). O tipo e a natureza dos excipientes utilizados na preparação de sólidos orais são dois fatores que determinam a velocidade e a extensão na qual o fármaco vai ser absorvido, uma vez que limitam a liberação e consequente dissolução do fármaco (VILLANOVA\& SÁ, 2007).

Segundo Gil e Brandão (2007), a importância dos excipientes em medicamentos é indiscutível: podem funcionar como diluentes ou solventes e ainda atuar garantindo ou interferindo na estabilidade ou propriedades físicas, químicas ou biológicas de insumos farmacêuticos. Diante dessas importantes considerações, verifica-se a preocupação com a escolha correta dos excipientes na RDC n. ${ }^{\circ} 87 / 2007$ (BRASIL, 2008): "Os excipientes devem ser padronizados de acordo com a compatibilidade das formulações descrita em compêndios oficiais/ farmacopéias/publicações científicas indexadas." Porém, neste estudo, não foi possível constatar se houve alguma interferência, pois nos ensaios de determinação do teor os valores também não foram satisfatórios para duas amostras analisadas.

Dentre as análises realizadas, ao lado do teste de dissolução, certamente a determinação do teor se constitui numa das mais importantes, uma vez que está diretamente relacionada com a quantidade de princípio ativo presente na forma farmacêutica e responsável pelo sucesso terapêutico. Em se tratando de antibióticos, teores baixos podem levar a um tratamento ineficiente do paciente, bem como a possibilidade de desenvolvimento de resistência por parte dos micro-organismos frente às "subdoses" presente nos medicamentos, enquanto teores acima dos valores permitidos podem acarretar quadros de intoxicação.

Foi realizado o doseamento por ensaio microbiológico, método da difusão em ágar (cilindros em placas). O doseamento de antibióticos por ensaios 
microbiológicos tem sido largamente utilizado por traduzir de maneira satisfatória a potência antibacteriana dos mesmos, embora requeiram um maior número de cuidados por parte do analista e um maior número de dados para a obtenção dos resultados, em relação aos métodos físico-químicos em geral (HEWITT, 1977). No entanto, são os mais indicados quando existe a necessidade de confirmação da eficácia terapêutica, principalmente para substâncias de origem biológica, como é o caso de vitaminas e antibióticos (PINTO et al., 2003; MORENO \& SALGADO, 2007).

Os teores inferiores aos permitidos nas amostras $\mathrm{C}$ e D alertam para a necessidade de total rigor nos procedimentos de pesagem, homogeneização e cálculos para o preparo de formas farmacêuticas manipuladas, bem como a necessidade de avaliar a pureza e integridade das matérias-primas no momento do recebimento, pois se os seus teores já forem baixos, é impossível que o produto acabado apresente teor dentro dos limites especificados.

Porém, para a análise de variação de peso médio, um possível erro na pesagem do princípio ativo pode não interferir nos resultados, pois a falta do fármaco é compensada com excesso de excipiente. Por outro lado, tal fato pode levar à "subdose" e, por consequência, à ineficácia terapêutica, o que contribui para a rejeição dos medicamentos manipulados por parte dos pacientes, persistindo o pensamento errôneo de que são menos eficazes que os industrializados.

Outro fator que pode ter contribuído para os baixos teores de amoxicilina encontrados está relacionado com a correção do teor de princípio ativo. Segundo Ferreira (2002), não há uma regra fixa que estabeleça a necessidade ou não de correção, porém, deve sempre ser baseada no produto farmacêutico de referência que foi primeiramente patenteado e com o qual foram feitos todos os ensaios farmacológicos. Essas correções, relacionadas com o ajuste do teor, envolvem a compensação da hidratação, de um sal ou de uma diluição da substância através do uso de fatores de correção ou de equivalência (ANFARMAG, 2000; ANTUNES, 2002).
No caso da matéria-prima amoxicilina, a mesma é obtida comercialmente na forma trihidratada, devendo o seu teor ser corrigido antes da pesagem para o preparo dos medicamentos (fator $=1,15$ ). No entanto, muitos profissionais ainda não atentam para a necessidade dessas correções, o que implica dosagem errada e, consequentemente, uma não conformidade passível de sanções legais (FERREIRA, 2002).

\section{Conclusão}

O presente trabalho chama a atenção para um maior controle dos medicamentos manipulados, principalmente de antibióticos amplamente usados, como a amoxicilina, desde a análise da matériaprima até o produto acabado. A implantação das boas práticas de manipulação e do controle de qualidade pelas farmácias magistrais é fator importantíssimo, uma vez que as mesmas desempenham papel decisivo na elaboração de formulações adaptadas segundo as necessidades de cada paciente, de custo mais baixo e maior facilidade posológica, vantagens que somente o medicamento manipulado pode oferecer. Porém, é imprescindível que esses medicamentos apresentem os quesitos de qualidade exigidos aceitáveis, a fim de contribuir para a sua segurança e eficácia terapêutica.

\section{Agradecimentos}

Os autores agradecem à Ariston Química e Farmacêutica Ltda. (São Paulo, Brasil) pela doação da substância de referência, ao Laboratório de Controle Biológico da Faculdade de Ciências Farmacêuticas e ao apoio financeiro do PACD-FCFAr-UNESP, FUNDUNESP, FAPESP e CNPq.

\section{REFERÊNCIAS}

AGUIAR, G; FARIA, L.G.; FERRAZ, H.G; SERRA, C.H.R.; PORTA, V. Avaliação biofarmacotécnica in vitro de formas farmacêuticas sólidas contendo doxiciclina. Br J Pharm Sci, v.41, São Paulo, n.4, p.451-458, 2005. 
ANFARMAG. Manual de equivalência. São Paulo: Anfarmag; 2000. 20p.

ANTUNES, D.J. Farmácia de manipulação: noções básicas. São Paulo: Tecnopress; 2002. 140p

BRASIL. Resolução RDC n. ${ }^{\circ} 87$ de 21 de novembro de 2008. Altera o regulamento técnico sobre Boas Práticas de Manipulação em farmácias. Diário Oficial da União, 24 nov 2008

FARMACOPÉIA BRASILEIRA. 4. ed. São Paulo: Atheneu, 2001. Parte I. p.5.1.1-5.1.5. Parte III. P.7676.1, 5.5.2.17.

FERREIRA, A.O. Guia prático da farmácia magistral. 2. ed. Juiz de Fora, 2002. 845p.

GIL, E.S.; BRANDÃO, A.L. Excipientes: suas aplicações e controle físico-químico. 2. ed. São Paulo: Pharmabooks, 2007. 285p.

GIL, E.S.; MACHADO, A.A. Ensaios de qualidade. In: GIL, E.S.; ORLANDO, R.M.; MATIAS, R.; SERRANO, S.H.P. Controle físico-químico de qualidade de medicamentos. Campo Grande: Uniderp, 2005. cap.13, p.215-242.

HEWITT, W. Microbiological Assay. New York: Academic Press, 1977. 284p.

KOHLER, L.F.; NASCIMENTO, H.D.; SCHWENGBER, E.L.L.; BANDEIRA, Z.M.P.; PAZIN, G.Y.; MACHADO, S.R.P. Avaliação biofarmacotécnica e perfil de dissolução de comprimidos de dipirona: equivalência farmacêutica entre medicamentos de referência, genéricos e similares. Rev Brás Farm, Rio de Janeiro, v.90, n.4, p.309315, 2009.

LINSBINSKI, L.M.; MUSIS, C.R.; MACHADO, S.R.P. Avaliação da equivalência farmacêutica de comprimidos de captopril. Ver. Bras. Farm, Rio de
Janeiro, v.89, n.3, p.214-219, 2008.

MALESUIK, M.D.; CARDOSO, S.G.; LANZANOVA, F.A.; BAJERSKI, L.; DORIGONI, E. Desenvolvimento de teste de dissolução e estudo comparativo de comprimidos e cápsulas magistrais contendo anlodipino. Rev Ciênc Farm Básica Apl, Araraquara, v.27, n.1, p.37-49, 2006.

MARTINDALE: Guía completa de consulta farmaco-terapéutica. 2. ed. Barcelona: Pharma Editores, 2006. 2950p.

MORENO, A.H.; SALGADO, H.R.N. Microbiological assay for ceftazidime injection. JAOAC Int, v.90, p.1379-1382, 2007.

NICHOLS, W.K. Antiinfecciosos. In: GENNARO, A.R. Remington: a ciência e a prática da farmácia. 20. ed. Rio de Janeiro: Guanabara Koogan, 2004. cap.87, p.1584-1589.

NUNAN, E.A.; GOMES, M.J.V.M.; REIS, A.M.M. Controle de qualidade de produtos farmacêuticos. In: GOMES, M.J.V.M.; REIS, A.M.M. Ciências farmacêuticas: uma abordagem em farmácia hospitalar. São Paulo: Atheneu, 2003. cap.14, p.251-271.

PETRI, W.A. Antimicrobial agents: penicillins, cephalosporins, and other -lactam antibiotics. In: HARDMAN JG, LIMBIRD LE. Goodman Gilman: the pharmacological basis of therapeutics. 11th. ed. New York: McGraw Hill, 2006. cap. 8, p.12061213.

PINHO, J.J.R.G.; STORPIRTIS, S. Estudo comparativo "in vitro" das propriedades biofarmacotécnicas de comprimidos de cloridrato de metformina comercializados no Brasil. Br. J Pharm Sci, São Paulo. v.37, n.1, p.95-105, 2001.

PINTO, T.J.A.; KANEKO, T.M.; OHARA, M.T. 
PAULO et al.

Controle biológico de qualidade de produtos farmacêuticos, correlatos e cosméticos. 2. ed. São Paulo: Atheneu, 2003. 325p.
VILLANOVA, J.C.O; SÁ, V.R. Excipientes: guia prático para padronização. São Paulo: Pharmabooks, 2007. 115p.

RECEBIDO EM 18/8/2011

ACEITO EM 29/11/2011 